\title{
ACTIVATED CARBON FIBERS DERIVED FROM SEA BALLS FOR THE USE AS SUPERCAPACITOR ELECTRODES
}

\author{
1,2Stefan BREITENBACH, ${ }^{1}$ Christoph UNTERWEGER, ${ }^{2}$ Achim Walter HASSEL, ${ }^{1}$ Christian FÜRST \\ ${ }^{1}$ Wood K plus - Kompetenzzentrum Holz GmbH, Linz, Austria, EU, s.breitenbach@wood-kplus.at \\ ${ }^{2}$ Institute of Chemical Technology of Inorganic Materials (TIM), Johannes Kepler University Linz, Linz, \\ Austria, EU
}

https://doi.org/10.37904/nanocon.2021.4308

\begin{abstract}
Sea balls (pillae marinae) were impregnated with diammonium hydrogen phosphate (DAHP), carbonized, and activated using carbon dioxide or steam. Thus, activated carbon fibers (ACFs) with unique morphology and specific surfaces of $243 \mathrm{~m}^{2} \mathrm{~g}^{-1}$ were produced. These ACFs were studied as electrode materials for supercapacitors that achieved specific capacities of $38 \mathrm{~F} \mathrm{~g}^{-1}$ in an organic electrolyte, resulting in specific energy for the supercapacitor of $9.7 \mathrm{~W} \mathrm{~h} \mathrm{~kg}^{-1}$.
\end{abstract}

Keywords: Activated carbon, electrode materials, supercapacitor, energy storage, sea balls, pillae marinae

\section{INTRODUCTION}

Energy storage is a key technology in the ongoing efforts to combat climate change. Supercapacitors are highly regarded energy storage devices due to their ability to absorb and release large amounts of energy very quickly. They are also characterized by their long service life of over 1 million charging cycles and low maintenance costs [1-3]. In this type of energy storage, the mostly carbon-based electrode materials are of central interest.

A promising material for supercapacitor electrodes is activated carbon fibers (ACFs). These ACFs have a high specific surface area, a well-suited pore structure, and possess excellent conductivity in the electrode due to their fiber shape, as we were able to find out in previous work [4-6]. When ACFs are used in electrode materials, high-purity substances such as viscose fibers, pitch fibers, or polyacrylonitrile fibers are usually used. These precursors have to be synthesized in advance in a complex process.

In this study, sea balls will be used as a starting material for the production of ACFs. In contrast to other starting materials for ACFs, no complex manufacturing process is required here; the sea balls are a naturally occurring, biological raw material. They are produced by the wave action in the sea by tearing out and felting dead parts of the seagrass (often neptune grass). When they are washed up on beaches they are removed by heavy machinery. Apart from its use as an insulating material, there are no known industrial applications for this raw material.

\section{MATERIALS AND METHODS}

The sea balls were collected on the beach of Talamone, Italy. They were washed in distilled water in a drum hoop mixer for $1 \mathrm{~h}$ and dried at $80{ }^{\circ} \mathrm{C}$ in a drying oven. Depending on the sample, treatment with a 10 wt.\% DAHP solution was performed (see Table 1). For this purpose, the samples were soaked in the $10 \mathrm{wt} . \%$ DAHP solution for $15 \mathrm{~min}$ and then dried at $80^{\circ} \mathrm{C}$ overnight. Carbonization was carried out in a chamber furnace (HTK8, Gero, Germany) with a heating rate of $10^{\circ} \mathrm{C} \mathrm{min}{ }^{-1}$ to $850^{\circ} \mathrm{C}$ under nitrogen atmosphere. Before cooling, the samples were held isothermally at the target temperature for $30 \mathrm{~min}$. Activation was carried out in a rotary 
kiln (RSR-B 120/500/11, Nabertherm $\mathrm{GmbH}$, Germany). Prior to use, $\mathrm{N}_{2}$ was used to purge the apparatus at a flow rate of $100 \mathrm{I} \mathrm{h}^{-1}$. Samples were then heated from room temperature to the desired activation temperature $T$ under an $\mathrm{N}_{2}$ flow rate of $50 \mathrm{Ih}^{-1}$. To ensure that the temperature was uniform throughout the reaction chamber, the sample was kept isothermal under the nitrogen flow for $30 \mathrm{~min}$. Then, the $\mathrm{N}_{2}$ flow was terminated and replaced by $\mathrm{CO}_{2}$ at the desired flow rate $\mathrm{Q}\left(80 \mathrm{I} \mathrm{h}^{-1}\right)$. The completion of the activation process was marked by stopping the $\mathrm{CO}_{2}$ flow and restarting the $\mathrm{N}_{2}$ flow until the oven cooled down to room temperature.

Table 1 Overview of the prepared samples

\begin{tabular}{|c|c|c|}
\hline Sample & Sample treatment & Activation conditions \\
\hline SB_165 & Washing, drying; carbonization & $\mathrm{T}=870{ }^{\circ} \mathrm{C} ; \mathrm{Q}=80 \mathrm{Ih}^{-1} ; \mathrm{t}=165 \mathrm{~min}$ \\
\hline SB_DAHP_165 & $\begin{array}{c}\text { Washing, drying; } \\
\text { impregnation with a } 10 \text { wt.\% DAHP soultion; } \\
\text { drying; carbonization }\end{array}$ & $\mathrm{T}=870^{\circ} \mathrm{C} ; \mathrm{Q}=80 \mathrm{I} \mathrm{h}^{-1} ; \mathrm{t}=165 \mathrm{~min}$ \\
\hline SB_DAHP_285 & $\begin{array}{l}\text { Washing, drying; } \\
\text { impregnation with a } 10 \text { wt.\% DAHP soultion; } \\
\text { drying: carbonization }\end{array}$ & $\mathrm{T}=870^{\circ} \mathrm{C} ; \mathrm{Q}=80 \mathrm{I} \mathrm{h}^{-1} ; \mathrm{t}=285 \mathrm{~min}$ \\
\hline
\end{tabular}

The morphology of the samples was investigated using Scanning Electron Microscopy (SEM) with Phenom ProX (Thermo Fisher Scientific, USA). The chemical composition was determined by using energy dispersive $\mathrm{X}$-ray spectroscopy (EDX) by using the same instrument. The acceleration voltage was $15 \mathrm{kV}$ and a backscattered electron detector (BSD) was used.

The specific surface area of the activated sea balls was determined using physical adsorption of nitrogen at $196{ }^{\circ} \mathrm{C}$ on an automatic volumetric sorption analyzer AutosorbiQ MP-XR (Quantachrome Instruments, USA) using the Brunauer-Emmet-Teller (BET) method. The adsorbed gas volume was measured at a relative pressure range of $0.1-0.3$ using $40-50 \mathrm{mg}$ of sample. Prior to the measurements, the samples were outgassed at $300{ }^{\circ} \mathrm{C}$ for $4 \mathrm{~h}$ under vacuum.

The electrode production can be found elsewhere [6,7]. The cells were assembled using a Swagelok@-type 2electrode test cell with two symmetrical ACF electrodes as a counter and working electrode soaked with a $1 \mathrm{M}$ triethylmethylammonium tetrafluoroborate (TEMA BF4, >98.0\%, TCI Deutschland GmbH, Germany) solution in propylene carbonate (PC, 99.5\%, Acros Organics N.V., Belgium) as an electrolyte with a separator (Celgard $₫ 3401$, Celgard, USA) between them. A C-coated aluminum foil (z-flo 2651, Coveris Management $\mathrm{GmbH}$, Austria) was used as a current collector. All cells were assembled under nitrogen atmosphere avoiding moisture and oxygen. Cyclic voltammetry (CV) and galvanostatic discharge curve (GDC) measurements were performed using a potentiostat (Vertex.One, Ivium Technologies BV, The Netherlands). The gravimetric capacitance $\mathrm{C}_{s}$ was determined by $\mathrm{CV}$ and GDC using the following equations (1) and (2):

$C_{S}=\frac{\int_{V_{1}}^{V_{2} i d V}}{2 m_{E} v}$

$C_{S}=\frac{2 I t}{m_{E} \Delta V}$

The specific capacitance $C_{s}$ of one electrode is determined by the integral $\int_{V_{1}}^{V_{2}} i d V$ of the positive part of the $5^{\text {th }} \mathrm{CV}$ curve, limited by the $V_{2}$ and $V_{1}$ of the cell voltage $\Delta V$, scan rate $v$ and the mass of the active material $m_{E}$ of one electrode. For the GDC measurements, $C_{S}$ is calculated using the current $I$, the discharge time $t, m_{E}$ and $\Delta V$. Energy density $E_{S}$ and power density $P_{S}$ for the device were calculated using equations (3) and (4):

$E_{S}=\frac{1}{8} C_{S, G D C}(\Delta V)^{2}$

$P_{S}=\frac{E_{S}}{t}$ 


\section{RESULTS AND DISCUSSION}

The sea balls are $3-7 \mathrm{~cm}$ in diameter before carbonization and consist of a dense mesh of fibers (Figure 1). This structure is retained even after carbonization.
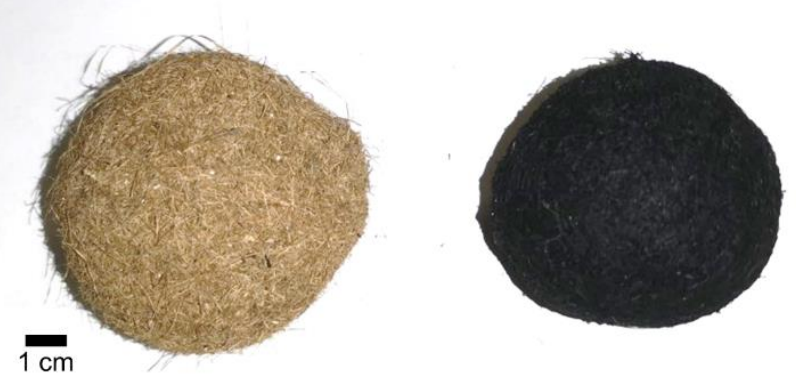

Figure 1 Impregnated sea ball before and after carbonization

The morphology of the sea balls after carbonization and after activation (SB_DAHP_165) was studied by SEM (Figure 2). In the case of the impregnated samples, the fiber structure is preserved both after carbonization and after activation by carbon dioxide. Without the DAHP treatment, the sea ball disintegrates during activation, leaving only ash and no carbon structure. The fibers differ strongly in thickness and length (see Figure 2a). At the fracture points of the fibers, it can be seen that the fibers possess a unique honeycomb-like structure.
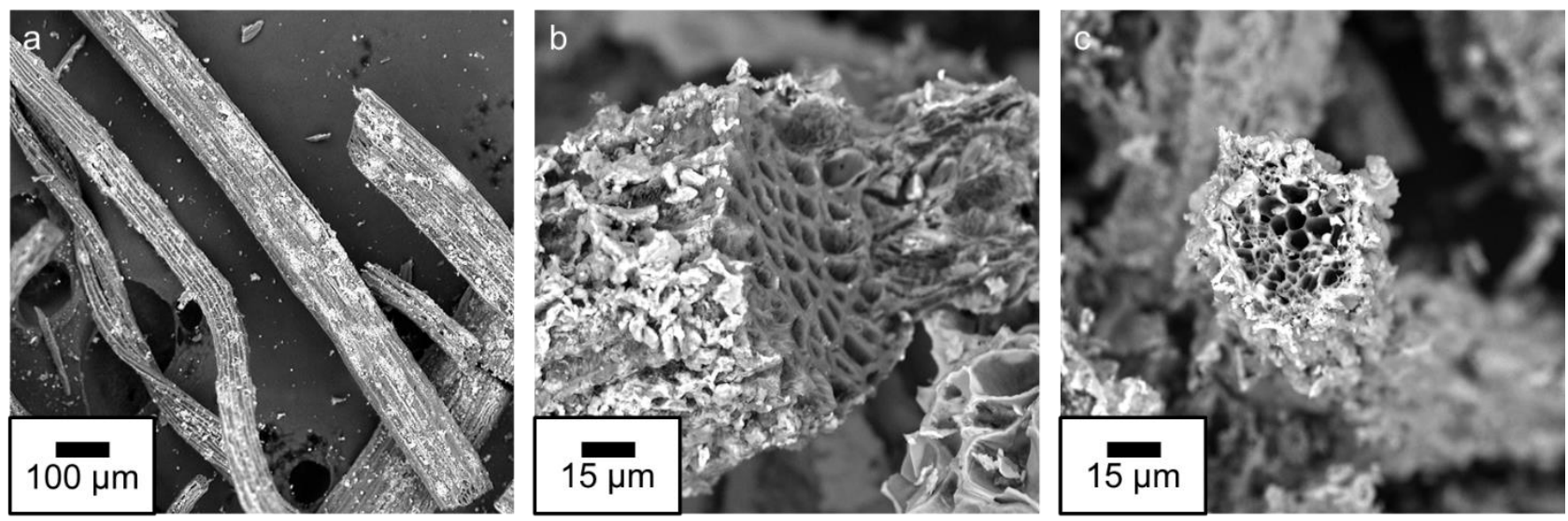

Figure 2 SEM micrograph of the carbonized ( $a$ and $b$ ) and the activated sea ball (b)

After activation, only the samples treated with DAHP form a carbon structure. The yield after 165 min activation time is $68.4 \%$, the specific surface area of the sample is $200 \mathrm{~m}^{2} \mathrm{~g}^{-1}$. With the longer activation time, the activation yield decreases to $33.9 \%$, but the specific surface area increases to $243 \mathrm{~m}^{2} \mathrm{~g}^{-1}$.

Table 2 Yield of the activation step, specific surface areas, and total pore volumes of the activated samples.

\begin{tabular}{|c|c|c|c|}
\hline Sample & Yield of the acticvation $/ \%$ & Specific surface area $/ \mathbf{~ m}^{\mathbf{2}} \mathbf{g}^{\mathbf{1}}$ & Total pore volume $/ \mathbf{c m}^{\mathbf{3}} \mathbf{g}^{\mathbf{- 1}}$ \\
\hline SB_165 & - & - & - \\
\hline SB_DAHP_165 & 68.4 & 200 & 0.13 \\
\hline SB_DAHP_285 & 33.9 & 243 & 0.15 \\
\hline
\end{tabular}

For further characterization, test cells were prepared from the ACFs and examined by CV and GDC. The sample activated for 165 min reached a maximum specific capacitance of $17 \mathrm{~F} \mathrm{~g}^{-1}$ at $\mathrm{CV}$ at the lowest scan rate of $2 \mathrm{mV} \mathrm{s}^{-1}$. The sample activated for $285 \mathrm{~min}$ showed a maximum specific capacitance of $28 \mathrm{~F} \mathrm{~g}^{-1}$. With 
increasing scan rate the specific capacitance decreased to $13 \mathrm{~F} \mathrm{~g}^{-1}$ at $300 \mathrm{mV} \mathrm{s}^{-1}$. For the specific capacitances calculated from the galvanostatic measurements (Figure 3b), the sample SB_DAHP_165 reaches a maximum value of $33 \mathrm{~F} \mathrm{~g}^{-1}$, while the sample reaches a value of $38 \mathrm{~F} \mathrm{~g}^{-1}$. The longer activated DAHP-impregnated sea ball also reaches the highest specific energies, calculated per test cell, of $9.7 \mathrm{~W} \mathrm{~h} \mathrm{~kg}^{-1}$ and the highest specific power of $3800 \mathrm{~W} \mathrm{~kg}^{-1}$ (Figure 3c).
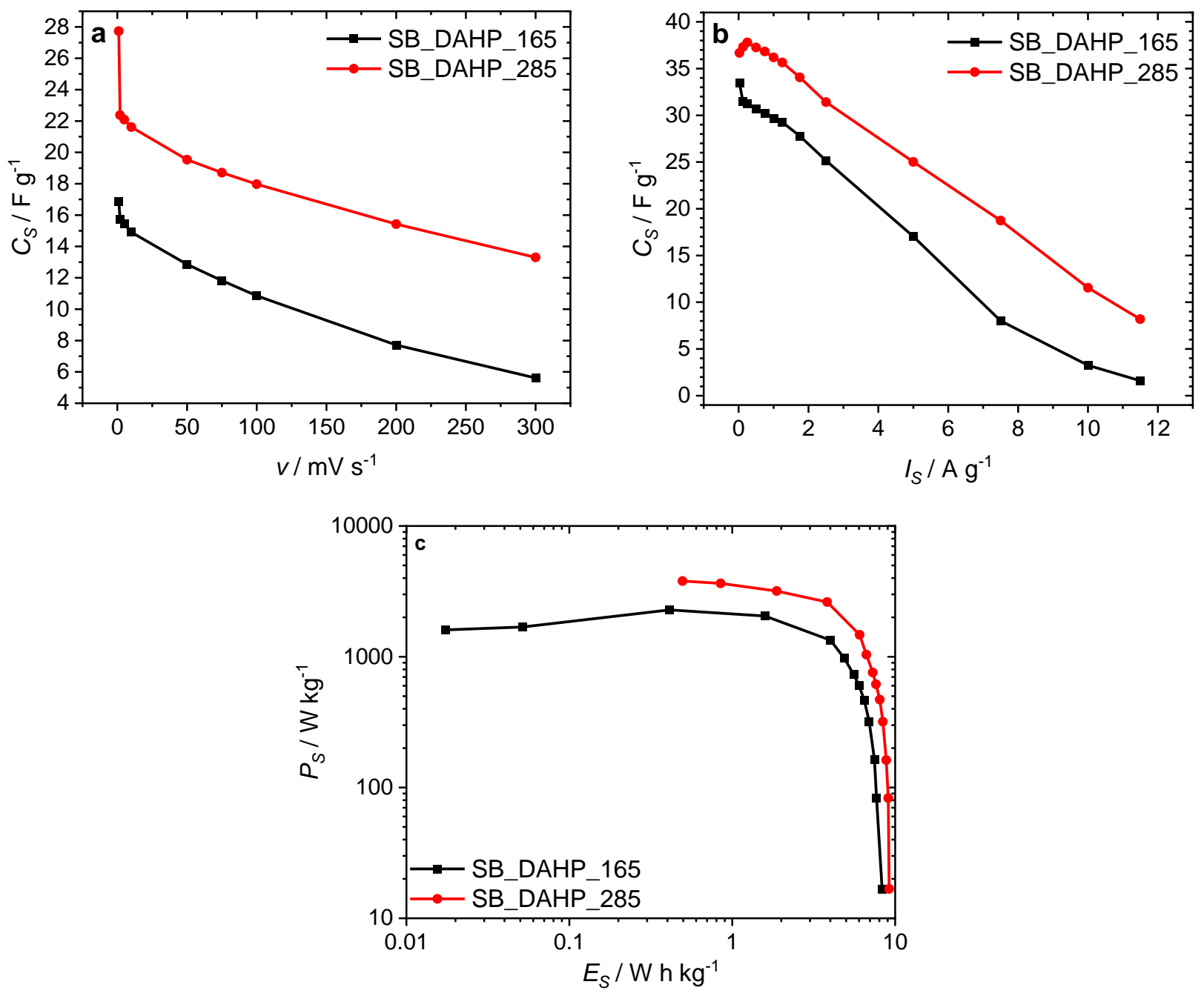

Figure 3 Specific capacitance per electrode $\mathrm{Cs}_{\mathrm{s}}$ derived from CV (a) and from GDC (b) as well as specific power Ps and specific energy Es derived by GDC (c)

\section{CONCLUSION}

Sea balls could be successfully used to produce ACFs that can be used as electrode material for supercapacitors. It was shown that the use of an impregnate is essential, otherwise no ACFs could be obtained. In the prepared AFCs, the unique honeycomb-like porous macroporous structure from the precursor remains intact. Overall, it can be easily seen that the higher specific surface area achieved by the longer activation results in higher specific capacities, powers, and energies. The achieved capacities per electrode of $38 \mathrm{~F} \mathrm{~g}^{-1}$ are relatively low compared to other precursors, but the achieved specific energy density of $17 \mathrm{~W} \mathrm{~h} \mathrm{~kg}^{-1}$ per test cell is promising. 


\section{ACKNOWLEDGEMENTS}

The authors wish to thank the European Regional Development Fund (EFRE) and the province of Upper Austria for financial support of this study through the program IWB 2014-2020 (project BioCarb-K). The authors would also like to thank Sarah Neustl for her assistance with the practical work.

\section{REFERENCES}

[1] ENOCK, T.K., KING'ONDU, C.K., POGREBNOI, A., JANDE, Y.A.C. Status of Biomass Derived Carbon Materials for Supercapacitor Application. Int. J. Electrochem. 2017, pp. 1-14.

[2] HAO, L., LI, X., ZHI, L. Carbonaceous electrode materials for supercapacitors. Adv. Mater. 2013, vol. 25, pp. 3899-3904.

[3] MURRAY, D.B., HAYES, J.G. Cycle Testing of Supercapacitors for Long-Life Robust Applications. IEEE Trans. Power Syst. 2015, vol. 30, pp. 2505-2516.

[4] PANDOLFO, A.G., HOLLENKAMP, A.F. Carbon properties and their role in supercapacitors. J. Power Sources. 2006, vol. 157, pp. 11-27.

[5] BEGUIN, F., FRACKOWIAK, E. Supercapacitors: Materials, systems, and applications. Weinheim:Wiley, 2013.

[6] BREITENBACH, S., LUMETZBERGER, A., HOBISCH, M.A., UNTERWEGER, C., SPIRK, S., STIFTER, D., FÜRST, C., HASSEL, A.W. Supercapacitor Electrodes from Viscose-Based Activated Carbon Fibers: Significant Yield and Performance Improvement Using Diammonium Hydrogen Phosphate as Impregnating Agent. C. 2020, vol. 6, pp. 17-29.

[7] BREITENBACH, S., GAVRILOV, N., PASTI, I., UNTERWEGER, C., DUCHOSLAV, J., STIFTER, D., HASSEL, A.W., FÜRST, C. Biomass-derived carbons as versatile materials for energy-related applications - capacitive properties vs. oxygen reduction reaction catalysis. C. 2021, vol. 7, pp. 55-70. 